\title{
$\mathrm{PH} 103_{\text {actualiad }}$
}

\section{El ICOM apuesta por el renacimiento del sector museístico con sus Proyectos de Solidaridad}

\begin{abstract}
El Consejo Internacional de Museos (ICOM) lanzó, entre el 12 de octubre y el 13 de diciembre de 2020, una convocatoria de Proyectos de Solidaridad. El objetivo fue apoyar a los profesionales de los museos de todo el mundo para adaptarse a los desafíos planteados por la pandemia a través de proyectos que apuntalen la resiliencia, explorando nuevos modelos prometedores para la práctica museística durante y tras la crisis sanitaria. Ocho proyectos fueron seleccionados. Tal fue la calidad y la cantidad de las propuestas recibidas que una segunda convocatoria a Proyectos de Solidaridad fue lanzada en marzo de 2021.
\end{abstract}

Fernando Avakian | Consejo Internacional de Museos (ICOM)

URL de la contribución <http://www.iaph.es/revistaph/index.php/revistaph/article/view/4864>

El Consejo Internacional de Museos (ICOM) es, desde hace décadas, una institución insoslayable en el panorama cultural global. Como tal, el ICOM tiene una posición privilegiada para responder, en su campo de acción, ante un desafío de talla planetaria como lo fue -y lo sigue siendo- la pandemia de la COVID-19.

Creado en 1946, el ICOM es una organización no gubernamental mundial que establece estándares profesionales y éticos para las actividades de los museos. Como foro de expertos, hace recomendaciones sobre cuestiones relacionadas con el patrimonio cultural, promueve el desarrollo de capacidades e incentiva la profundización de conocimientos en su campo de acción. Dada su amplia representación (alrededor de 50.000 miembros de todo el mundo), ICOM es en gran medida la voz de los profesionales de los museos en el escenario internacional y busca crear conciencia cultural pública a través de redes globales y programas de cooperación, así como en organizaciones internacionales e intergubernamentales (entre ellas, la Unesco).

En 2020, entre diversas iniciativas para proporcionar apoyo a su red de museos ${ }^{1}$, fuertemente afectados por las medidas restrictivas que prácticamente paralizaron el sector cultural, la institución lanzó, entre el 12 de octubre y el 13 de diciembre de 2020, una convocatoria de Proyectos de Solidaridad. El objetivo de la misma fue apoyar a los profesionales de los museos de todo el

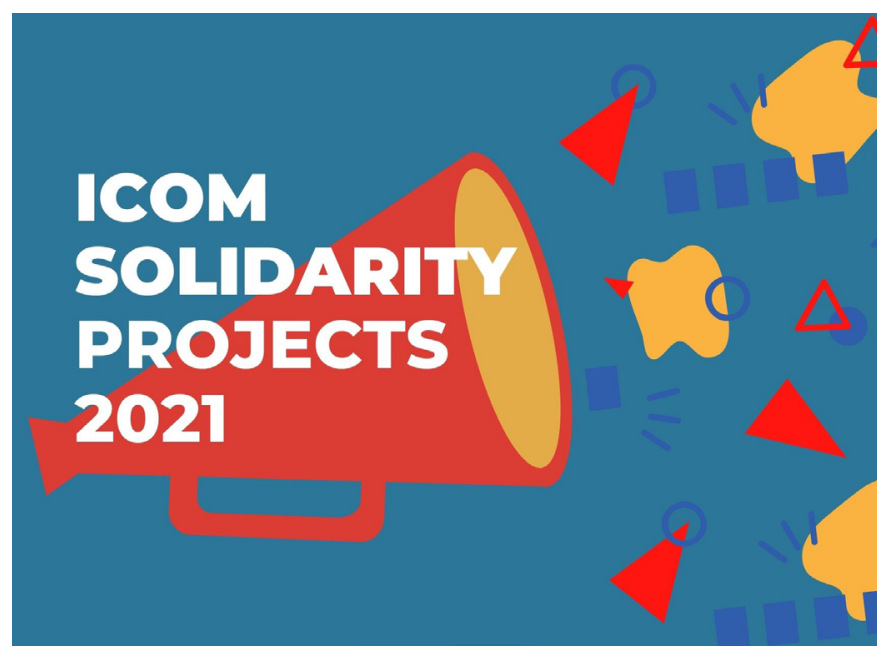

Cartel de la convocataria 2021

mundo para adaptarse a los desafíos planteados por la pandemia a través de proyectos que apuntalen la resiliencia de los museos, explorando nuevos modelos prometedores para la práctica museística durante y tras la crisis sanitaria. Fiel a su slogan "Los museos no tienen fronteras, tienen una red", el ICOM buscó, a través de esta convocatoria, financiar proyectos que aglutinen actores y museos de diferentes partes del globo y de horizontes culturales distintos a fines de fomentar la cooperación internacional en el ámbito museístico.

La naturaleza de los proyectos recibidos varía grandemente. Algunas de las propuestas se centraron en ejem- 
plos de mejores prácticas sobre la organización del trabajo en museos para adaptarlos a las nuevas circunstancias, mientras que otros exploraron cómo mejorar la relación entre los museos y su comunidad, tanto durante el período de confinamiento como después de la pandemia. Teniendo en cuenta que una buena parte de la actividad de los museos (y del mundo de la cultura en general) se tornó hacia lo virtual, se intentó hacer hincapié en proyectos que pudieran difundirse en línea. Varias propuestas tenían como idea de fondo recrear el rol social activo que los museos pueden tener en la comunidad; lo interesante de tal enfoque es que la pandemia sirve como disparador de un proceso que trasciende el contexto de la misma, reposicionando tales instituciones en el seno de la sociedad. Otros proyectos abordan los desafíos que enfrentan en particular los profesionales de los museos: el trabajo a distancia, el riesgo de perder el empleo, el panorama incierto del sector, etcétera.

Hubo asimismo propuestas que ponían el foco más bien en la seguridad de los visitantes al momento de apertura para asegurar un futuro sostenible de los museos tras las cuarentenas, así como en crear actividades que busquen generar ingresos adicionales para los museos, creando empleos y reorganizando las visitas y exposiciones.

Tras un concienzudo y riguroso estudio de las propuestas recibidas, el Comité de Examen de Subsidio

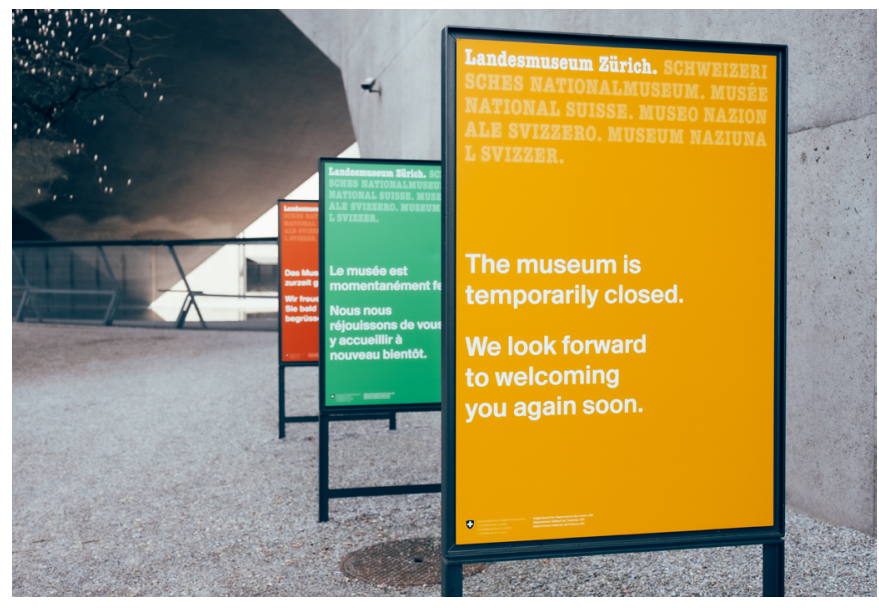

Swiss National Museum, cerrado en mayo de 2020 | foto Patrick Robert Doyle

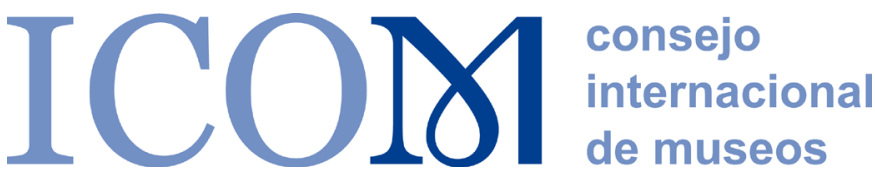

Estratégico (SAREC) del ICOM seleccionó los siguientes ocho proyectos para recibir financiación del ICOM. Se intentó respetar un balance geográfico y temático a la hora de la selección de las propuestas:

$>$ Ethical Collecting during the Pandemic: a shared space for museum professionals (presentado por el Comité Internacional del ICOM para las Colecciones, $\mathrm{COMCOL}$ ). Partiendo de una perspectiva cultural amplia, el proyecto tiene como objetivo explorar las similitudes y diferencias entre diferentes regiones con relación a la práctica del coleccionismo museístico en contextos pandémicos (incluyendo el actual) y otras experiencias históricas traumáticas.

> Clothing the Pandemic: Resiliency, Community \& Unity Expressed through an International Collaboration of the COVID-19 Facemask Project (presentado por el Comité Internacional de Museos y Colecciones de Vestuario, ICOM Costume). Este proyecto de investigación y exposición digital tiene como objetivo documentar y contextualizar el uso de mascarillas durante la pandemia de coronavirus de 2020-21. El proyecto conectará a los museos y conservadores internacionales que trabajan en este tema y vinculará virtualmente sus colecciones a un público global.

$>$ Los ruidos que somos: patrimonios sonoros de los Andes (presentado por el Comité Nacional del ICOM en Ecuador). Este proyecto busca conectar las comunidades y los patrimonios de museos del centro y la periferia de ciudades latinoamericanas conectadas por los Andes, sorteando las barreras físicas que hay entre el museo y ciertos públicos, acentuadas por el aislamiento social producto del COVID-19, y que impiden la apropiación de la ciudadanía de estos espacios.

> "Solidarités, musées: de quoi parle-t-on?" Cycle de 10 séances sur plateforme numérique (presentado por el 
Comité Nacional del ICOM en Francia). Se trata de un ciclo de seminarios, en idioma francés, que busca ser una herramienta de intercambio entre profesionales de los museos para repensar el período posterior al COVID19 a la luz del principio de la solidaridad.

> Museo para llevar (presentado por el Comité Nacional del ICOM en Costa Rica). Este proyecto aspira a crear exposiciones virtuales y un modelo de mediación replicable en otras instituciones, diseñando recursos audiovisuales para fomentar la visita a los museos en un ambiente de enseñanza y aprendizaje virtual en Centroamérica.

$>$ HELP/Heritage education new web formats and free licenses opportunities for dissemination, co-creation and open data (presentado por el Comité Nacional del ICOM en Italia). El proyecto HELP propone poner al servicio de la educación museística las licencias gratuitas y la información de libre acceso, que son un activo para la resiliencia de los museos.

$>$ INTERCOM Global Museum Leadership Study and Knowledge Platform (presentado por el Comité Internacional del ICOM sobre la gestión de museos, ICOM INTERCOM). Se trata de una serie de encuestas globales a directores/as de museos y su personal para estudiar la relación entre liderazgo y gestión de museos en el marco la crisis de COVID-19.

> Museum Tendencies and Perspectives: Focus on Lithuania and Latvia (presentado por el Comité Nacional del ICOM en Letonia). El proyecto pasa revista a las lecciones aprendidas por el sector museístico de Lituania y Letonia durante las restricciones de COVID-19 a fines de intentar atraer nuevas audiencias regionales.

Tal fue la calidad y la cantidad de las propuestas recibidas que una segunda convocatoria a Proyectos de Solidaridad fue lanzada a su vez el 18 de marzo de 2021. El 30 de abril finalizó el plazo de entrega de solicitudes y a partir del 31 de mayo se conocerá el nombre de los beneficiarios.

\section{NOTAS}

1. Para más información sobre las actividades del ICOM para apoyar los museos de todo el mundo durante la pandemia, visite: https://icom.museum/es/covid-19/ 